\title{
Kinematic Design of a Reconfigurable Deployable Canopy
}

\author{
G. Kiper ${ }^{1}$, F. Gürc̈̈ ${ }^{2}$, K. Korkmaz ${ }^{3}$ and E. Söylemez ${ }^{4}$ \\ ${ }^{1}$ İmir Institute of Technology,Turkey,e-mail: gokhankiper@iyte.edu.tr \\ ${ }^{2}$ Erciyes University, Turkey, e-mail: fulyagurcu@erciyes.edu.tr \\ ${ }^{3}$ İmir Institute of Technology,Turkey, e-mail: koraykorkmaz@iyte.edu.tr \\ ${ }^{4}$ Middle East Technical University,Turkey,e-mail: eres@metu.edu.tr
}

\begin{abstract}
A reconfigurable and deployable mechanism is proposed for a canopy which can also be used as a tent or a semi-open structure. The proposed single degree-of-freedom mechanism has four assembly modes. The conditions for deployment and reconfiguration of the mechanism are derived. These conditions impose three equality and two inequality constraints on the 11 design parameters of the mechanism. A virtual model of the mechanism is constructed in Excel for design and simulation purposes. A computational case study is presented.
\end{abstract}

Key words: kinetic architecture, deployable structures, canopy design, reconfigurable mechanisms.

\section{Introduction}

The term "reconfigurable" is used for several different meanings in the literature. Some authors use reconfigurable structure to describe movable systems which can attain different stable forms, like a chair which can transform into a ladder [1]. In this context, reconfigurable may be used interchangeably with transformable. In this study, what we mean by reconfiguration is assembly mode change for a mechanism. Also the word configuration is used for different concepts in various studies. In most mechanism science textbooks configuration is used as equivalent to assembly mode (Ex. [2]). Mason [3] defines a configuration of a system as the location of every point in the system, so that he can define the configuration space as a metric space comprising all configurations of a given system. On the other hand, Kuo et al. [4] use the configuration definition of Merriam-Webster Dictionary as "relative arrangement of parts or elements". According to this last definition, a Skotch-Yoke mechanism and a double slider mechanism with orthogonal 
slider axes have the same configuration [4]. In this study we use configuration interchangeably with assembly mode.

In most applications reconfiguration is undesirable, because it causes uncontrolled motion of a mechanism. However, recently some designs make use of reconfiguration in order for the mechanism to adapt to different tasks or service conditions. Even an ASME/IFToMM conference series is started about reconfigurable mechanisms and robots [5]. In MecArt - Kinetic Designs in Architecture group [6] in Iztech we recently started working on reconfigurable designs and the first design concept is presented as a reconfigurable deployable canopy design [7]. To our knowledge this is the first and only reconfigurable single degree-offreedom design in kinetic architecture. The design is not only reconfigurable, but also deployable, so that the mechanism has a compact state (Fig. 1a). The mechanism may be reconfigured to be used as a canopy (Fig. 1b) or a tent (Fig. 1c) or in a semi-open hybrid form (Fig. 1d). The planar mechanism demonstrated in Fig. 1 is used as a module and several such planar modules can be combined with parallelogram loops in order to obtain spatial assemblies (Fig. 2). In [7] we presented the initial design with parallelogram loops. In this study we investigate alternate designs with general link dimensions.

(a)

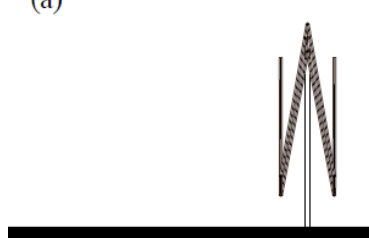

(b)

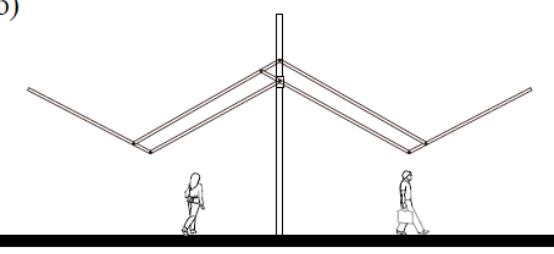

(c)

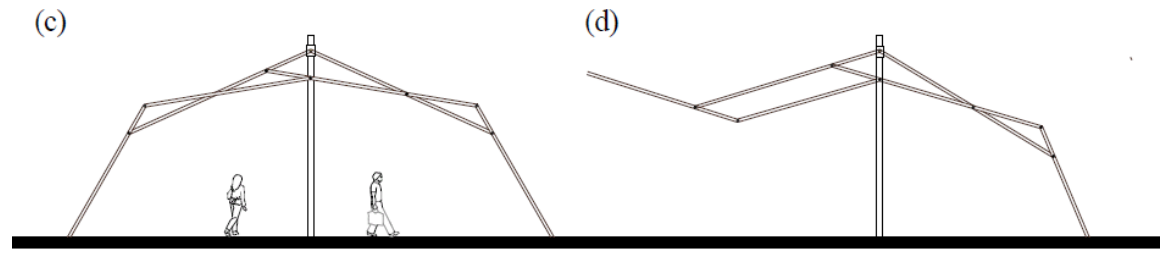

Fig. 1 Planar mechanism module in (a) compact form, (b) fully open (canopy) form, (c) fully closed (tent) form and (d) semi-open form 


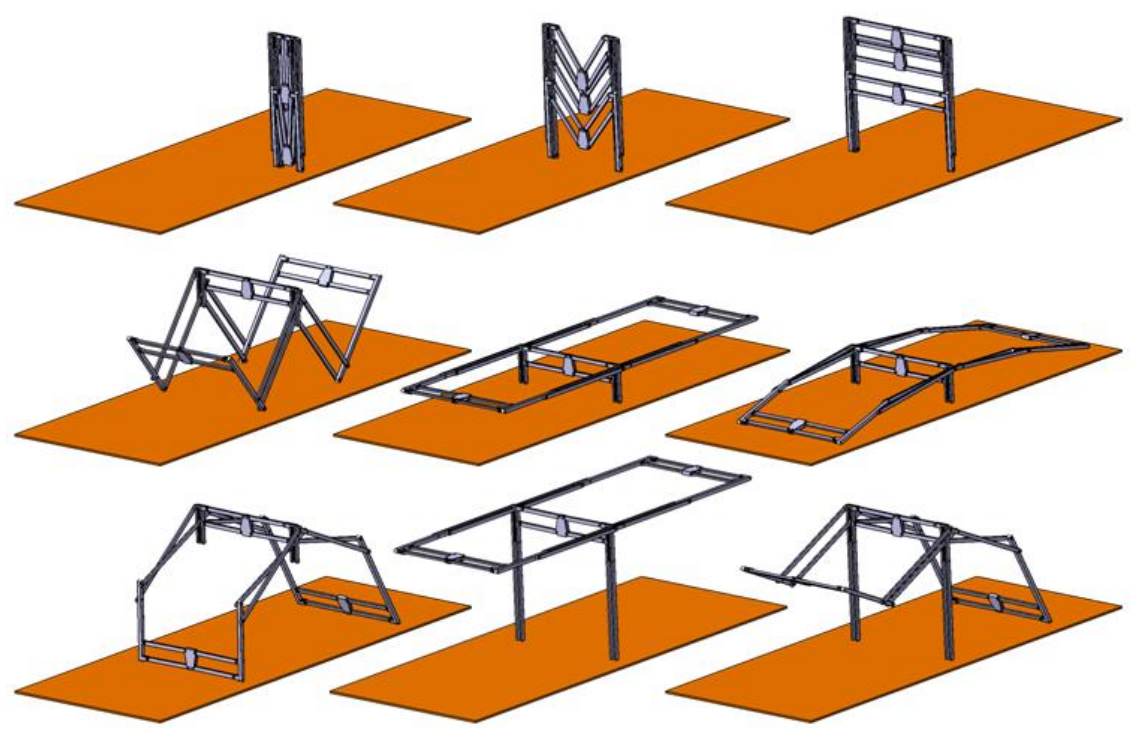

Fig. 2 The spatial assembly

\section{Kinematic model of the mechanism}

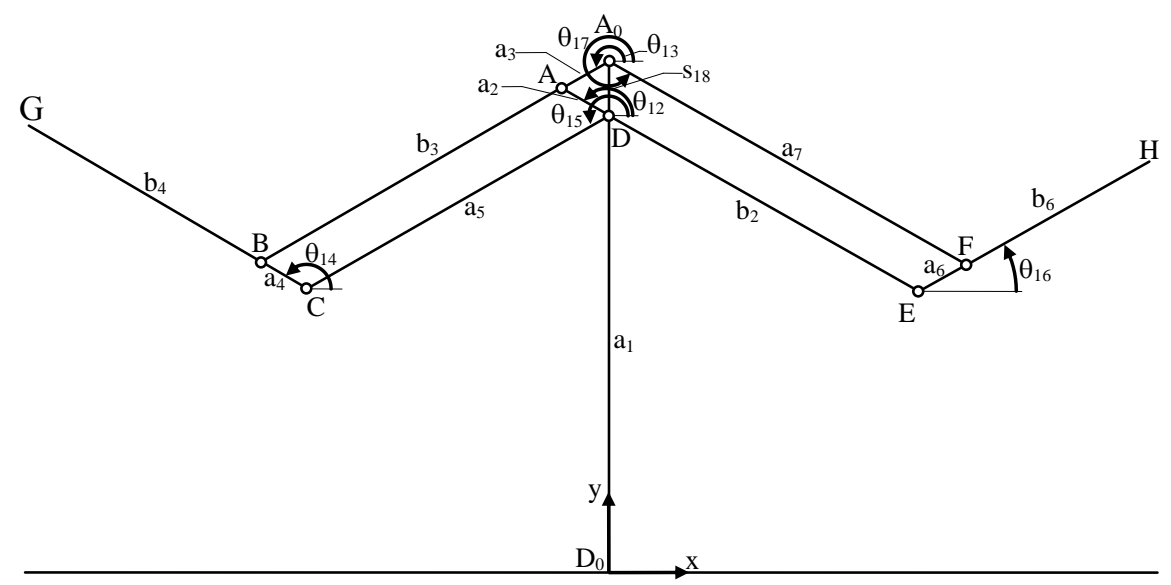

Fig. 3 Kinematic diagram of the mechanism 
The kinematic diagram of the planar mechanism is illustrated in Fig. 1. The reconfigurable mechanism comprises two four-bar loops and a slider-crank loop (Fig. 3). It has single degree-of-freedom with 8 links and 10 joints (The slider at joint D is not shown in Fig. 3). The design parameters of the mechanism are defined as $\left|\mathrm{A}_{0} \mathrm{D}_{0}\right|=\mathrm{a}_{1},|\mathrm{AD}|=\mathrm{a}_{2},|\mathrm{DE}|=\mathrm{b}_{2},\left|\mathrm{AA}_{0}\right|=\mathrm{a}_{3},|\mathrm{AB}|=\mathrm{b}_{3},|\mathrm{BC}|=\mathrm{a}_{4},|\mathrm{BG}|=\mathrm{b}_{4},|\mathrm{DC}|=$ $a_{5},|E F|=a_{6},|F H|=b_{6}$ and $\left|A_{0} F\right|=a_{7}$. The variable joint parameters are $\theta_{12}, \theta_{13}$, $\left|\mathrm{A}_{0} \mathrm{D}\right|=\mathrm{s}_{18}, \theta_{14}, \theta_{15}, \theta_{16}$ and $\theta_{17}$.

A parametric model of this mechanism is constructed in Microsoft Excel ${ }^{\circledR}$ environment. See [8] for use of Excel ${ }^{\circledR}$ in mechanism applications. Fig. 4 illustrates the design of the reconfigurable mechanism with Microsoft Excel ${ }^{\circledR}$. First of all, link length parameters $a_{1}, a_{2}, b_{2}, a_{3}, b_{3}, a_{4}, b_{4}, a_{5}, a_{6}, a_{7}$ are specified. Variable joint parameters $\theta_{12}, \theta_{13}, \mathrm{~s}_{18}, \theta_{14}, \theta_{15}, \theta_{16}, \theta_{17}$ are determined in row 17 using the Visual Basic macro functions explained in [9]. The joint coordinates are evaluated in columns $\mathrm{E}$ and $\mathrm{F}$. The input angle $\theta_{12}$ can be varied using the associated spin button and the graph of the mechanism can be animated.

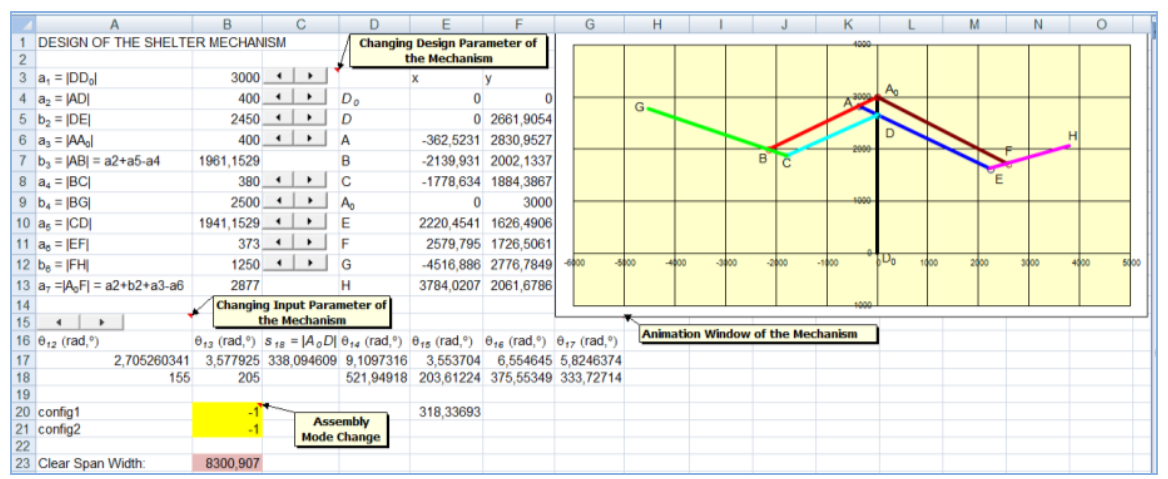

Fig. 4 Design of the reconfigurable mechanism with Microsoft Excel ${ }^{\circledR}$

Two configuration variables are defined in cells B20 and B21 for the two loops of the mechanism. These variables take the value 1 for the open configuration and -1 for the cross configuration of the four bar loops $\mathrm{ABCD}$ and $\mathrm{A}_{0} \mathrm{AEF}$. Also the clear span width (the distance between end points $\mathrm{G}$ and $\mathrm{H}$ when they are collinear on the ground in the fully closed form of the mechanism) is monitored in cell B23.

\section{Determining the link length dimensions}

The crucial part of the overall design process of reconfigurable deployable shelter is its geometric design. In order to have a fully compact configuration, the 
mechanism must obey a general deployability condition [10]. The deployability condition is that all of the joints of the mechanism are collinear in the folded configuration. The deployability conditions for the two four bar loops $\mathrm{ABCD}$ and $\mathrm{A}_{0} \mathrm{AEF}$ are as follows:

$$
\text { For loop ABCD: } \mathrm{a}_{2}+\mathrm{a}_{5}=\mathrm{a}_{4}+\mathrm{b}_{3}
$$

$$
\text { For loop } \mathrm{A}_{0} \text { AEF: } \mathrm{a}_{3}+\left(\mathrm{a}_{2}+\mathrm{b}_{2}\right)=\mathrm{a}_{6}+\mathrm{a}_{7}
$$

There are also some inequality constraints as design requirements. The main design requirement is reconfigurability. Reconfiguration is obtained through the dead center positions when links DC and $\mathrm{CB}$ are collinear for loop $\mathrm{ABCD}$ and $\mathrm{AE}$ and $\mathrm{EF}$ are collinear for loop $\mathrm{A}_{0} \mathrm{AEF}$. In order to have this collinearity, the following reconfigurability conditions should be satisfied:

$$
\text { For loop ABCD: } \mathrm{a}_{4}+\mathrm{a}_{5} \leq \mathrm{b}_{3}+\mathrm{a}_{2}
$$

$$
\text { For loop } A_{0} A E F: a_{2}+b_{2}+a_{6} \leq a_{7}+a_{3}
$$

Combining the reconfigurability conditions (3) and (4) with the deployability conditions (1) and (2):

$$
\begin{aligned}
& a_{4} \leq a_{2} \\
& a_{6} \leq a_{3}
\end{aligned}
$$

Reconfigurations of the two loops have to occur simultaneously, because if one of the loops reaches the dead center position before the other one, this other loop does not reach its dead center position. When the two loops simultaneously reach their dead center positions, the loops are instantaneously positioned as in Fig. 5.

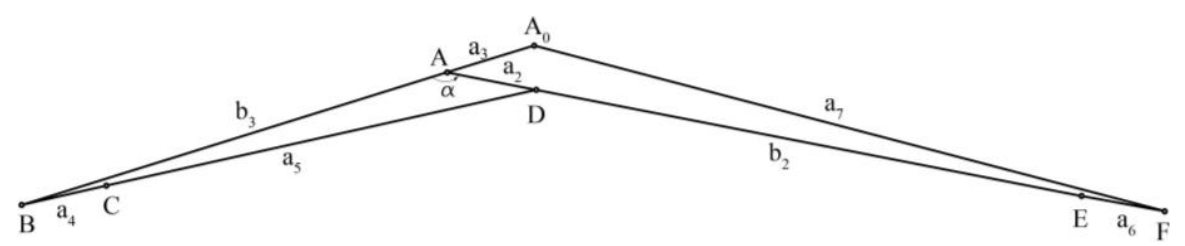

Fig. 5 The four-bar loops in dead center position

Writing cosine theorem for triangles $\mathrm{ABD}$ and $\mathrm{A}_{0} \mathrm{AF}$ in Fig. 5: 


$$
\begin{gathered}
\left(a_{4}+a_{5}\right)^{2}=a_{2}{ }^{2}+b_{3}{ }^{2}-2 a_{2} b_{3} \cos \alpha \Rightarrow \cos \alpha=\frac{a_{2}{ }^{2}+b_{3}{ }^{2}-\left(a_{4}+a_{5}\right)^{2}}{2 a_{2} b_{3}} \\
a_{7}^{2}=a_{3}^{2}+\left(a_{2}+b_{2}+a_{6}\right)^{2}-2 a_{3}\left(a_{2}+b_{2}+a_{6}\right) \cos (\pi-\alpha) \\
\Rightarrow \cos \alpha=\frac{a_{7}^{2}-a_{3}{ }^{2}-\left(a_{2}+b_{2}+a_{6}\right)^{2}}{2 a_{3}\left(a_{2}+b_{2}+a_{6}\right)}
\end{gathered}
$$

Combining Eqs. (7) and (8):

$$
\frac{a_{2}^{2}+b_{3}^{2}-\left(a_{4}+a_{5}\right)^{2}}{a_{2} b_{3}}=\frac{a_{7}^{2}-a_{3}^{2}-\left(a_{2}+b_{2}+a_{6}\right)^{2}}{a_{3}\left(a_{2}+b_{2}+a_{6}\right)}
$$

Eq. (9) shall be called the simultaneous reconfiguration condition. Eq. (9) imposes another restriction on the design parameters. In total there are two equality and three inequality constraints on the 11 design parameters. Due to the equality constraints, 8 of the 11 parameters can be selected freely. Here is a description of the design procedure: The dimension $\mathrm{a}_{1}$ is the height of the reconfigurable shelter and can be selected freely according to the design requirements. There are five relationships among the link length $a_{2}, b_{2}, a_{3}, b_{3}, a_{4}, a_{5}, a_{6}$ and $a_{7}$ of the two four-bar loops: deployability conditions (1) and (2), reconfigurability conditions (3) and (4), and the simultaneous reconfiguration condition (9). Due to the three equality constraints, among the 8 parameters defined above 5 of them can be selected independently. It is rational that $\mathrm{a}_{2}, \mathrm{a}_{3}, \mathrm{a}_{4}, \mathrm{a}_{6}$ are should be independent parameters to satisfy the inequality constraints (5) and (6). The remaining independent parameter can be selected among $b_{2}, b_{3}, a_{5}$ or $a_{7}$. For instance, let $b_{2}$ be selected as an independent parameter. From the deployability conditions two out of $b_{3}, a_{5}$ or $a_{7}$ are dependent on the others. Let $b_{3}$ and $a_{7}$ be dependent. So from (1) and (2)

$$
\begin{gathered}
\mathrm{b}_{3}=\mathrm{a}_{2}+\mathrm{a}_{5}-\mathrm{a}_{4} \\
\mathrm{a}_{7}=\left(\mathrm{a}_{2}+\mathrm{b}_{2}\right)+\mathrm{a}_{3}-\mathrm{a}_{6}
\end{gathered}
$$

$a_{5}$ should be solved from the simultaneous reconfiguration condition (9). Manipulating Eq. (9):

$$
a_{3}\left(a_{2}+b_{2}+a_{6}\right)\left[a_{2}^{2}+b_{3}^{2}-\left(a_{4}+a_{5}\right)^{2}\right]=a_{2} b_{3}\left[a_{7}^{2}-a_{3}^{2}-\left(a_{2}+b_{2}+a_{6}\right)^{2}\right]
$$


Substituting (10) and (11) in (12), expanding and simplifying:

$$
\begin{aligned}
& a_{3}\left(a_{2}+b_{2}+a_{6}\right)\left[a_{2}\left(a_{2}-a_{4}\right)+\left(a_{2}-2 a_{4}\right) a_{5}\right] \\
& =a_{2}\left(a_{2}-a_{4}+a_{5}\right)\left[\left(a_{2}+b_{2}\right)\left(a_{3}-2 a_{6}\right)-a_{3} a_{6}\right]
\end{aligned}
$$

Solving for $\mathrm{a}_{5}$ from (13):

$$
a_{5}=\frac{a_{2} a_{6}\left(a_{2}-a_{4}\right)\left(a_{2}+b_{2}+a_{3}\right)}{a_{3} a_{4}\left(a_{2}+b_{2}+a_{6}\right)-a_{2} a_{6}\left(a_{2}+b_{2}+a_{3}\right)}
$$

The remaining link lengths $b_{4}$ and $b_{6}$ are subject to two conditions: In fully closed configuration, points $\mathrm{G}$ and $\mathrm{H}$ must be in line with $\mathrm{D}_{0}$ and distance between $\mathrm{G}$ and $\mathrm{H}$ should be equal to the required clear span width. These requirements are satisfied by changing $b_{4}$ and $b_{6}$ in Excel using the associated spin buttons.

\section{Case study}

Consider a canopy design with a desired height $3.5 \mathrm{~m}$ and desired clear span width $15 \mathrm{~m}$. A proper set of link length dimensions according to the formulations in Section 3 are determined as: $\mathrm{a}_{2}=1 \mathrm{~m}, \mathrm{~b}_{2}=4.5 \mathrm{~m}, \mathrm{a}_{3}=1 \mathrm{~m}, \mathrm{~b}_{3}=6.663 \mathrm{~m}$ (from Eq. (10)) $\mathrm{a}_{4}=0.98 \mathrm{~m}, \mathrm{~b}_{4}=2.5 \mathrm{~m}, \mathrm{a}_{5}=6.643 \mathrm{~m}$ (from Eq. (14)), $\mathrm{a}_{6}=0.973 \mathrm{~m}, \mathrm{~b}_{6}=$ $1.18 \mathrm{~m}$ and $\mathrm{a}_{7}=5.527 \mathrm{~m}$ (from Eq. (11)). The span width is $15.032 \mathrm{~m}$. The fully closed and fully open forms of the designed mechanism are illustrated in Fig. 6.

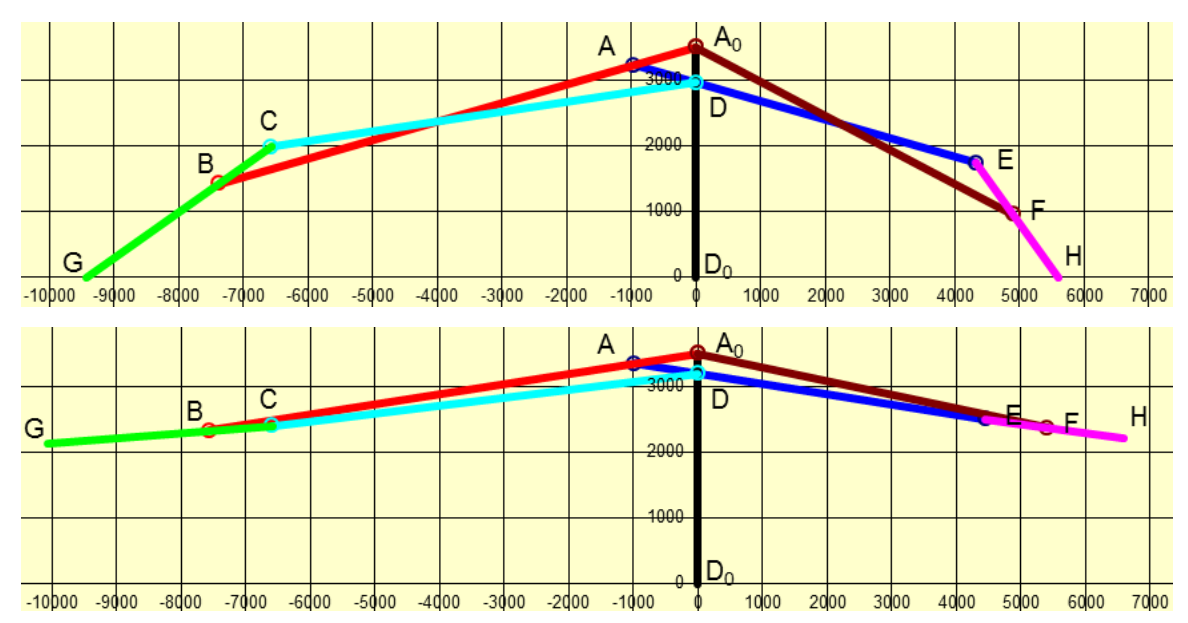

Fig. 6 Fully closed form of case study 


\section{Conclusions}

For the first time a reconfigurable single degree-of-freedom mechanism is proposed for an architectural application in this study. The 8-link mechanism is to be used as a deployable canopy which can transform into a tent or a semi-open form. The deployability, reconfigurability and simultaneous reconfiguration conditions for the mechanism are derived such that among 11 design parameters, 8 of them can be selected freely. In further studies we plan to devise means for obtaining reconfiguration of the mechanism manually or automatically.

\section{References}

5. Dai, J. S., Zoppi, M. and Kong, X. (Eds.): ASME/IFToMM International Conference on Reconfigurable Mechanisms and Robots REMAR 2009 (2009) Available via IEEEXplore ${ }^{\circledR}$ Digital Library. http://ieeexplore.ieee.org/xpl/mostRecentIssue.jsp?punumber $=5167202$

7. Gürcü, F., Korkmaz, K. and Kiper, G.: Design of a reconfigurable deployable structure. In: Proceedings of the First Conference Transformables 2013. Seville, pp. 145-149 (2014)

6. Korkmaz, K.: Mec-Art - Kinetic Designs in Architecture. http://mecart.iyte.edu.tr, last access: 06.03.2014

4. Kuo, C.-H., Dai, J. S. and Yan, H.S.: Reconfiguration principles and strategies for reconfigurable mechanisms. In: Dai, J. S., Zoppi, M. and Kong, X. (Eds.): ASME/IFToMM International Conference on Reconfigurable Mechanisms and Robots REMAR 2009, pp. 1-7 (2009)

10. Maden F., Korkmaz K. and Akgün Y.: A Review of Planar Scissor Structural Mechanisms: Geometric Principles and Design Methods. Archit. Sci. Rev., 54, 246-257 (2011)

3. Mason, M. T.: Mechanics of Robotic Manipulation (Series: Intelligent Robots and Autonomous Agents). MIT Press, p. 11 (2001)

8. Söylemez, E.: Using Computer Spreadsheets in Teaching Mechanisms. In: Proceedings of EUCOMES 08. Springer, pp. 45-53 (2008)

2. Söylemez, E. Mechanisms. $4^{\text {th }}$ Ed. METU Press (2009a)

9. Söylemez, E.: Appendix 2: Function Routines for Simple Mechanisms and Basic Trigonometry. In: Mechanisms. $4^{\text {th }}$ Ed. METU Press (2009b) Available via METU OpenCourseWare. http://ocw.metu.edu.tr/pluginfile.php/3961/mod_resource/content/12/appendices/ek2.htm

1. Weaver, J. M., Wood, K. L. and Jensen, D.: Transformation facilitators - a quantitative analysis of reconfigurable products and their characteristics. In: Proceedings of the ASME 2008 International Design Engineering Technical Conferences \& Computers and Information in Engineering Conference IDETC/CIE 2008, Brooklyn, NY, DETC2008-49891 (2008) 